\title{
Assessment of the Relationship Between Facial and Dental Midlines with Anatomical Landmarks of the Face and Oral Cavity
}

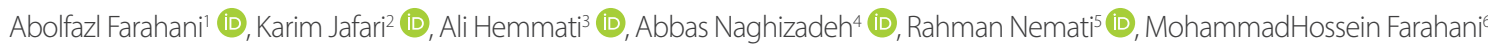 \\ 'Private Practice, Arak, Iran \\ ${ }^{2}$ Department of Prosthodontics, Ardabil University of Medical Sciences School of Dentistry, Ardabil, Iran \\ ${ }^{3}$ Private Practice, Zahedan, Iran \\ ${ }^{4}$ Department of Physical Education, Ardabil University of Medical Science School of Medicine, Ardabil, Iran \\ ${ }^{5}$ Department of Orthodontics, Ardabil University of Medical Sciences School of Dentistry, Ardabil, Iran \\ ${ }^{6}$ Dental Research Center, Institute of Dental Sciences, Shahid Beheshti University of Medical Sciences School of Dentistry, Tehran, Iran
}

Cite this article as: Farahani A, Jafari K, Hemmati A, Naghizadeh A, Nemati R, Farahani MH. Assessment of the Relationship Between Facial and Dental Midlines with Anatomical Landmarks of the Face and Oral Cavity. Turk J Orthod 2019; 32(4): 200-6.

\begin{abstract}
Objective: The purpose of the present study was to determine the facial anatomical landmarks, in order of accuracy, closest to the midline of the face, as well as oral cavity midline, and to specify which intraoral anatomical landmarks are closer to the dental midline.

Methods: Three commonly used anatomical landmarks including nasion, nose, and philtrum tips were marked clinically in 108 subjects. A frontal full-face digital image was used for midline analysis in accordance with the esthetic frame. Deviations from the facial and oral midlines were measured for the three clinical landmarks. Dental midline was considered as the fourth landmark. Alginate impressions were taken, and casts were analyzed under standardized conditions. The labial frenum and incisive papilla were marked. Cast images were taken and analyzed.

Results: Data showed difference between the mean ratios of the selected anatomical landmarks and the facial and oral midlines $(p \leq 0 / 05)$. The anatomical landmark hierarchies, in proximity to the facial midline, are commissural midlines, nasion, philtrum tip, nose tip, and dental midline, respectively. The anatomical landmark hierarchies, in proximity to the commissural midline, include dental midline, philtrum tip, nose tip, and nasion. The labial frenum was less deviated from the dental midline than the incisive papilla.

Conclusion: With respect to shortcomings, the results showed that all of the anatomical landmarks were deviated from the facial and oral midlines. The order of proximity of the anatomical landmarks to the facial midline was as follows: commissural midline, nasion, philtrum, and dental midline.
\end{abstract}

Keywords: Facial midline, dental midline, commissural midline, oral midlines

\section{INTRODUCTION}

Symmetry in face is known as one of the fundamental indicators of beauty $(1,2)$. It is defined as "correspondence in size, shape, and relative position of parts on opposite sides of a dividing line or median plane or about a center or axis (3)," but clinically, it means "existence of balance and coordination" (4). One of the components of facial symmetry is coordination of the dental and facial midlines that is an essential part of prosthetic rehabilitations and orthodontic treatments $(5,6)$.

During a smile, symmetrical teeth display plays an important role in creating a beautiful smile (4). However, in a pleasant smile, almost maxillary teeth are displayed, and coordination of the maxillary central incisors midline with the facial midline is more important than mandibular incisors. Nevertheless, coordination of the upper and lower arch dental midlines is necessary to achieve beauty and a proper occlusion, and in addition, it can increase 
the duration and complexity in orthodontic treatment cases (4). Anatomical landmarks including interpupillary distance, nasion, tip of the nose, philtrum, and center of the chin have been used to assess facial symmetry. One of the methods of midline determination is to determine the center of lip commissures and then drawing a perpendicular line, which is stated to be of higher accuracy (7). In some cases, such as asymmetric development, trauma, and facial neoplastic lesions where landmarks are changed, other landmarks should be used. In these cases, some intraoral landmarks, such as incisive papilla, labial frenum, and median palatal suture, are also suggested by researchers (8). The incisive papilla had the highest degree of compatibility with the midline of the face in a previous study (9). Previous studies are mainly based on the extent of the acceptable range of discrepancy between dental midline with facial midline that is approximately $2-3 \mathrm{~mm}$, and they did not have a definite reference to the midline $(1,10,11)$. In two separate studies $(12,13)$ in the same results, $70 \%$ of the dental midline compatibility with the facial midline has been reported. The major problem of studies in this area is the shortage of sufficient scientific evidence regarding the relationship between facial midlines and anatomical landmarks in the mouth. Therefore, the purpose of the present study was to investigate the relationship between facial and dental midlines and anatomical landmarks of the face and mouth.

\section{METHODS}

A total of 108 students from a local university participated in the present study. The study included 54 male and 54 female subjects. The age of the students was between 20 and 25 years. Inclusion criteria were the following: (1) no anterior tooth extraction, (2) no orthodontic treatment, (3) no restorative or prosthetic treatment, (4) no cosmetic surgery on the jaws or rhinoplasty, (5), no crowding or spacing in the upper and lower dental arches, and (6), no obvious asymmetry or defect on the face and dental arch. Using a marker (Faber Castell Grip 1583 Marker, Germany), three points were drawn on the nasion, in the middle of the philtrum, and the tip of the nose with an approximate diameter of half a millimeter. A digital camera (Canon EOS 1300D, EF 100 mm MACRO Lens, Taiwan) with spot flash was set at the 12 o'clock position. The camera diaphragm was set in automatic mode at 4.5, and the camera was mounted on a tripod (CT-2491 Carbon Fiber Tripod, USA), switched into the automatic mode, and then placed at a standard distance of $1.5 \mathrm{~m}$ from the subject. The room light conditions were similar for each photo. The photos were taken from the subjects in a seated position while they were wearing a social smile. The position of the head is adjusted in natural head position (NHP). The lens height of the camera on the tripod was adjusted the same as the height of the subject's eyes when they were sitting straight on the chair. The subjects were asked to look directly toward the camera, and the subjects' heads were positioned vertically and horizontally in a standard manner (Figure 1).

Care was taken to ensure that the subject does not rotate his head especially around the vertical axis, since this rotation around the vertical axis causes the midline to move against the direction of the axis of rotation. Four pictures were taken from each subject, and among these, the following photos were set aside: (1) having head rotation, (2) asymmetric eyes, (3) clinical marker sign was incorrect or unreadable, and (4) low-quality and low-resolution photos; the best photos were then selected. The images were transferred to Photoshop CS6 software for processing.

It is almost impossible for the midline of the face to define in both dynamic movements and esthetic. A rectangle known as the esthetic frame was used to define the face midline. This area is defined as a zone where esthetic items, such as the midline and the occlusal plane inclination, and smile parameters are readily recognizable. The upper border runs from the outer contour of one eye and extends toward the outer contour of the other eye. This line helps in detecting the rotation of the head around the sagittal axis. External borders were drawn from the outer corner of the eyes so that they are perpendicular to the horizontal line and are exactly parallel to each other. The lower border is drawn parallel to the upper border on the lower rim of the lower lip. These four lines complete the "esthetic frame." Two defaults were considered for drawing the esthetic frame. First, the midline of the esthetic frame was considered equivalent to the midline of the face. Second, soft tissues outside this area, such as the cheeks, buccal soft tissue, and frontal tissue, have a small effect on midline perception. Buccinator muscle hypertrophy, weight, and size of the forehead are factors that can influence midline perception. Dental midline is defined as the vertical line that runs from the tip of the embrasure between two central incisors of the maxilla to the relevant contact area, which is the midline parallel to the midline of the esthetic frame. Oral commissure midline is defined as the midline between the corners of the subject's lips during smiling. The relative facial midline (RFV) and the relative commissural midline (RCV) serve as tools for evaluating the relationship between anatomical landmarks and defined midlines. Three vertical lines were drawn along each of the anatomical points that were clinically determined. The fourth line was drawn along the dental midline of the subjects. The RFV is defined as an indicator of the proximity of a landmark to the facial midline. It is measured from the external border of the frame to the facial midline as shown by the letter $F$. The measured distance from the outer boundary of the frame to the nasion is shown as the $n$ variable. Then, the RFV is obtained by dividing $\mathrm{n}$ by F. Similarly, the RFVs were obtained for the next landmarks including nose tip (t), point in the middle of the philtrum

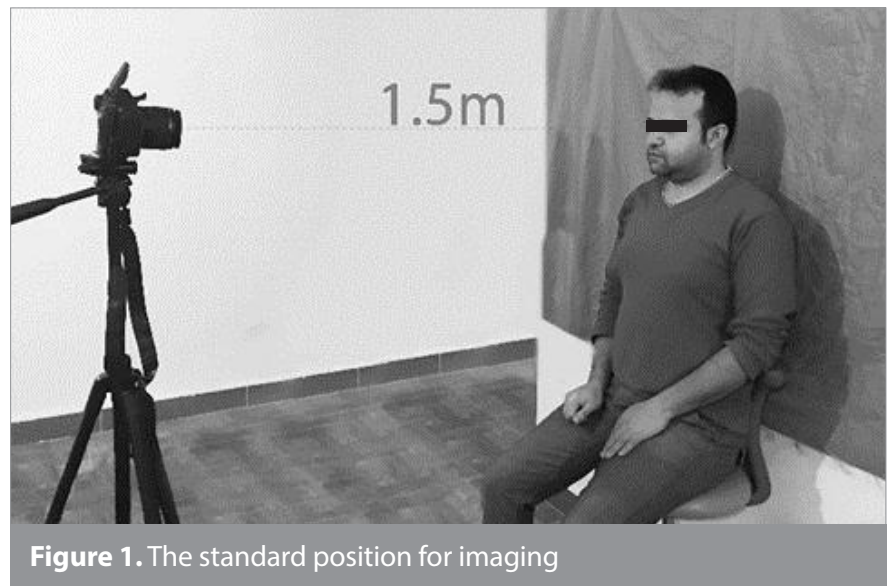


(p), and dental midline $(d)(d / F, p / F$, and $t / F)$, and the numbers were recorded. To investigate the relationship between anatomical landmarks and commissural midline, a point was determined at the center of each commissure, and a line was drawn between these two points. A point in the middle of the intercommissure line was assumed, and from that point, a line parallel to the midline of the esthetic frame was drawn and considered as the commissural midline. The RCV as an indicator of the proximity of an anatomical landmark to the commissural midline (center of the mouth) is considered as point $C$. In fact, the distance from point $C$ to each of the commissures was considered as a variable. The measured distances from nasion, philtrum, tip of the nose, and dental midline to the commissures were considered as variables $(n x),(p x),(t x)$, and $(d x)$, respectively. Then, RCVs were obtained by dividing these points into $C$, and data were recorded $(n x / C$, $\mathrm{tx} / \mathrm{C}, \mathrm{px} / \mathrm{C}$, and $\mathrm{dx} / \mathrm{C}$ ). The measured distances from the external border of the esthetic frame to the central point between the commissures were defined as a variable called $C x$.

This is a standard denominator for all the anatomical landmarks in the esthetic frame, and there is no need to match the image with the subject's face (Figure 2, 3).

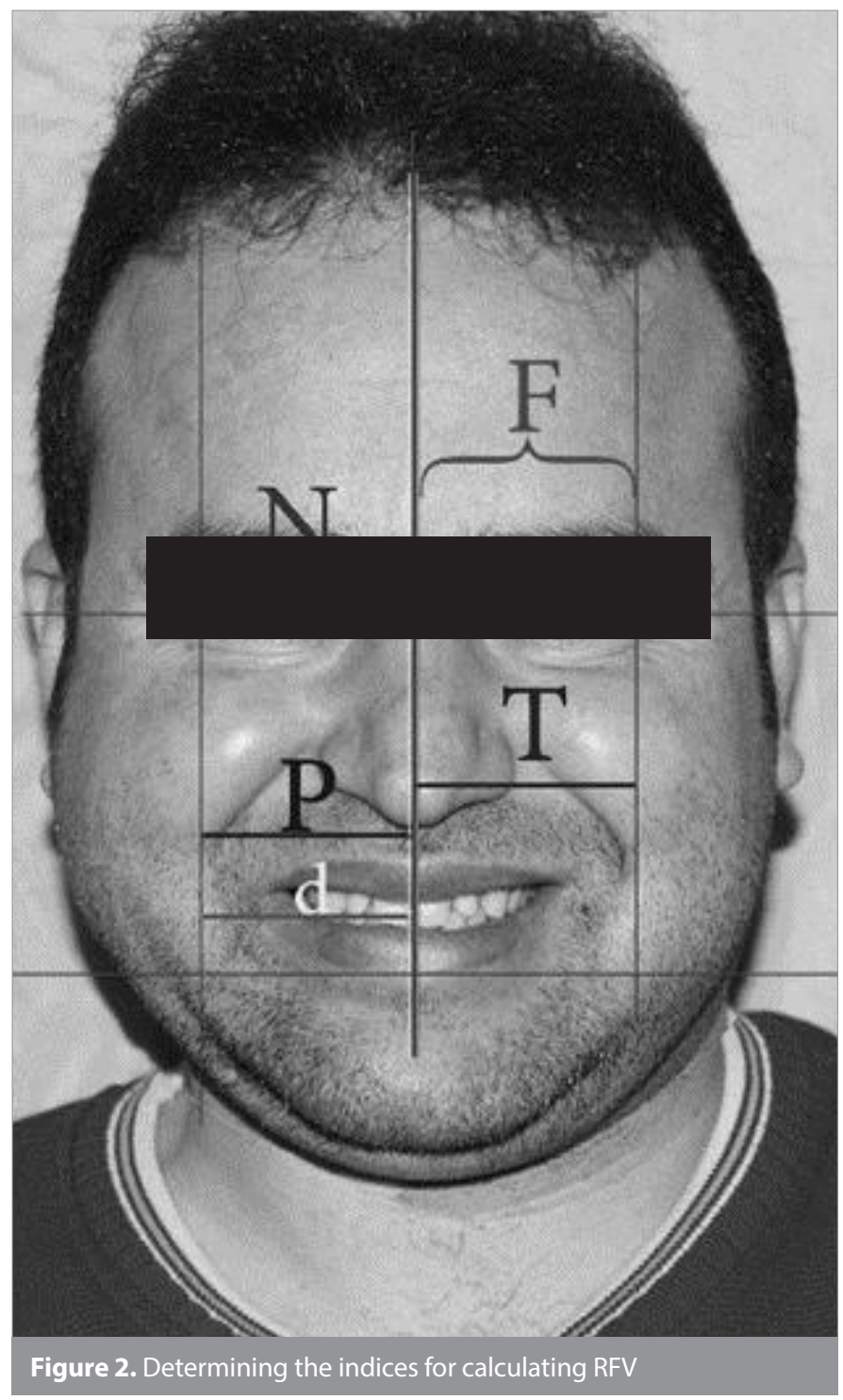

RFV1 and RCV1: Nasion relationship with the midline of the face and the commissural midline.

RFV2 and RCV2: Nose tip relationship with the midline of the face and the commissural midline.

RFV3 and RCV3: Relationship of the tip of the philtrum with the midline of the face and the commissural midline.

RFV4 and RCV4: Dental midline relationship with the midline of the face and the commissural midline.

RFV5: Relationship of the commissural and facial midlines.

Therefore, by considering the symmetry in all of the five aforementioned subjects, it can be deduced that the RFVs and the RCVs are equal to each other and to 1. The right or left border of the esthetic frame to commissure is selected based on the direction of anatomical landmarks classification. Therefore, the shorter distance from the outer border of the esthetic frame is always selected. Hence, the RFV and the RCV are never $>1$. For each subject, an alginate impression was taken and immediately poured with

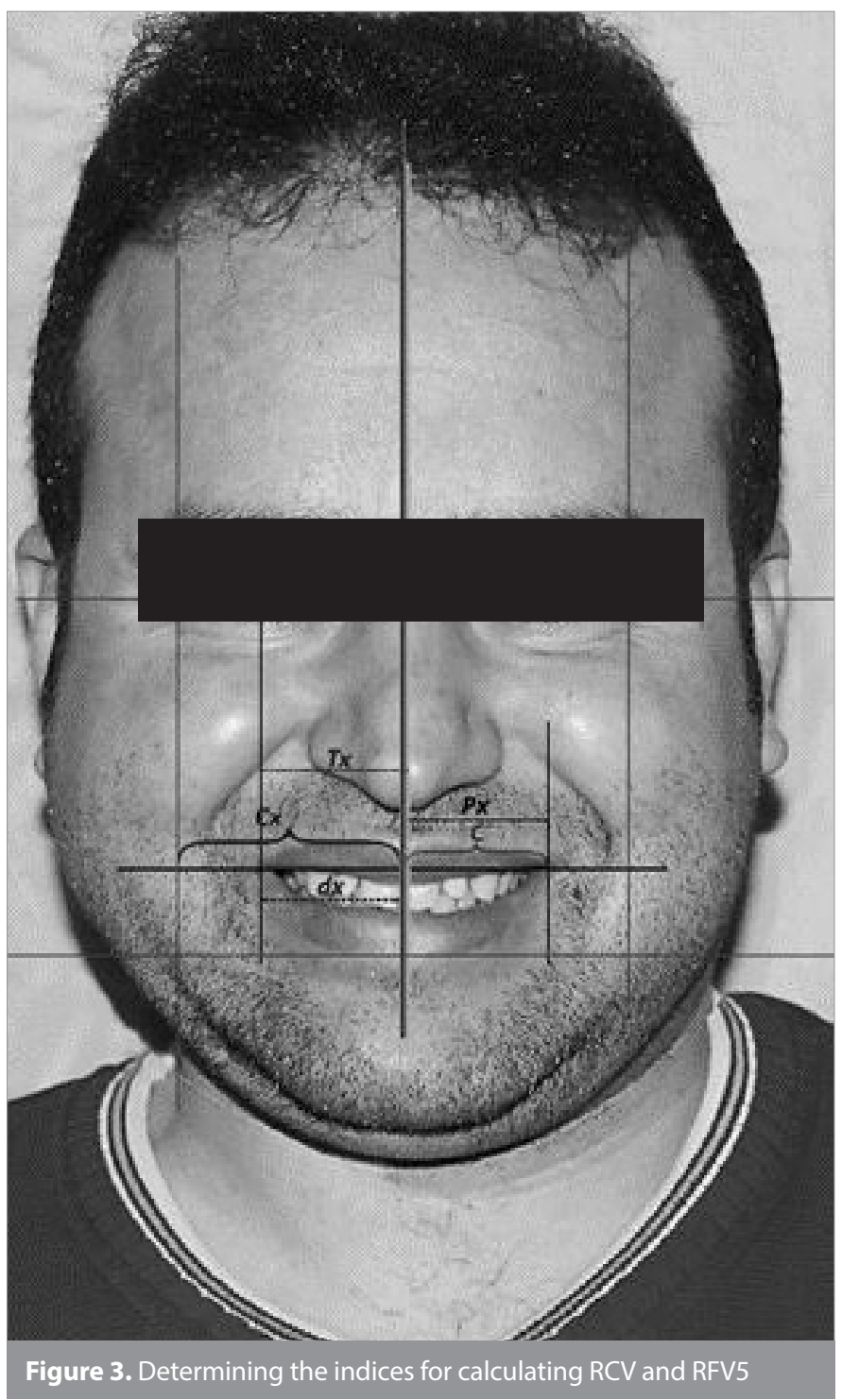


type 3 plaster (premiumplusuk ${ }^{\mathrm{TM}}$, UK). When the bases are placed on a flat horizontal surface, the casts were placed on the smooth surface of the occlusal edge to standardize the casts in accordance with an occlusal plane parallel to the horizontal plane. Then, by a ruler, several points around the casts were marked with a pencil (Mars ${ }^{\circledR}$ Lumograph ${ }^{\circledR}$ black 100B) at a $30 \mathrm{~mm}$ height. The points were connected by one line, and the casts were orthodontically trimmed according to the line drawn (Figure 4).

Anatomical landmarks including the anterior point of the incisive papilla (IPa), posterior point of the incisive papilla (IPb), anterior point of the labial frenum (LFa), and posterior point of the labial frenum (LFb) were drawn on the casts. The casts were placed on a flat black slab inside a cardboard box that places the camera at a height of $200 \mathrm{~mm}$. The digital camera was adjusted in such a way that the axis of the lens was in the vertical and downward directions relative to the occlusal plane. Digital data were processed with Photoshop CS6 software. The IPa, IPb, LFa, and LFb points were digitally connected with one line, and the line extends on both sides. The

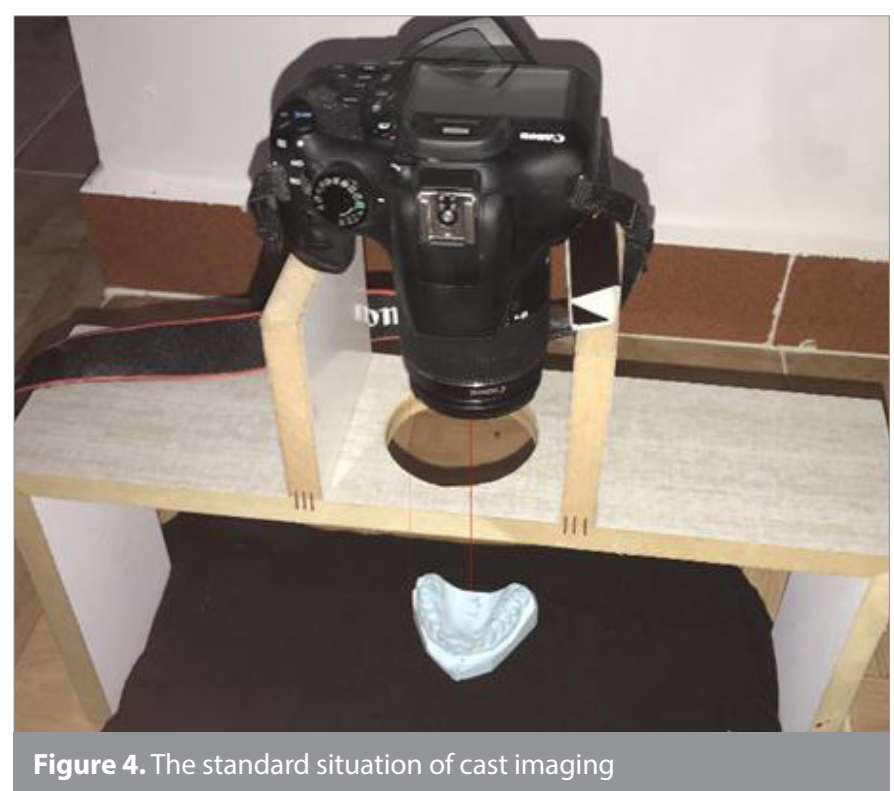

contact area of the two central teeth is a line drawn in the same way that in fact is the dental midline. The distance of each of the two lines drawn from the labial frenum and incisive papilla to the dental midline was measured, and the results were recorded.

Ethics committee approval was received for this study from the Ethics Committee of Ardabil University of Medical Sciences. Written informed consent was obtained from the patients who participated in this study.

\section{Statistical Analysis}

Data were analyzed by one-sample t-test and t-test for the independent groups using Statistical Package for Social Sciences version 24.0 (IBM Corp.; Armonk, NY, USA). The level of statistical significance was considered as 0.05 .

\section{RESULTS}

All variables in the present study had normal distribution using kurtosis test. For each variant, the results of one-sample t-test are shown in Table 1-3. The analysis showed that the difference between the mean ratio of each anatomical landmark and the midline of the face was statistically significant $p<0.001$. There was a significant difference (Table 4 ) between the mean ratios of the dental midline, commissural midline, and philtrum with the facial midline in males and females $p<0.05$. Moreover, the results showed that there is a statistically significant difference (Table 5) between the mean ratios of the nose tip with the commissural midlines in males and females $p<0.001$. The results of independent-samples t-test for the male and female groups are shown in Table 4-6.

\section{DISCUSSION}

Since the human face is not primarily symmetrical, there are no single rules for midline diagnosis, but noncoincident midlines are readily detectible by the patients (12). Lay people tend to be less sensitive to midline changes than dentists, but as problems

Table 1. Comparison between mean ratios of RFV 1-5 with criterion number

\begin{tabular}{lcccccc} 
Variant & mean & Stand Criterion & Dev Number & df & t & p \\
RFV1 (Nasion) & $0 / 96$ & $0 / 03$ & 1 & 107 & $-14 / 02$ & $0.001^{*}$ \\
RFV2 (Tip of the nose) & $0 / 96$ & $0 / 03$ & 1 & 107 & $-12 / 99$ & $0.001^{*}$ \\
RFV3 (Philtrum) & $0 / 96$ & $0 / 03$ & 1 & 107 & $-14 / 07$ & $0.001^{*}$ \\
RFV4 (Dental midline) & $0 / 95$ & $0 / 03$ & 1 & 107 & $-13 / 95$ & $0.001^{*}$ \\
RFV5 (Midline of commissures) & $0 / 97$ & $0 / 02$ & & & $-12 / 73$ \\
*One Sample t- test; $p \leq 0 / 05$ & & & & & \\
\hline
\end{tabular}

Table 2. Comparison between mean ratios of RCV1-4 with criterion number

\begin{tabular}{|c|c|c|c|c|c|c|}
\hline Variant & mean & Stan Dev & Criterion Number & df & $\mathbf{t}$ & $\mathbf{p}$ \\
\hline RCV1 (Nasion) & $0 / 94$ & $0 / 05$ & 1 & 107 & $-13 / 36$ & $0.001^{*}$ \\
\hline RCV2 (Tip of the nose) & $0 / 95$ & $0 / 05$ & 1 & 107 & $-11 / 72$ & $0.001^{*}$ \\
\hline RCV4 (Dental Midline ) & $0 / 97$ & $0 / 03$ & 1 & 107 & $-11 / 51$ & $0.001^{*}$ \\
\hline
\end{tabular}


Table 3. Comparison between mean ratios of IP and FL with criterion number

\begin{tabular}{lcccccc} 
Variant & mean & Stan Dev & Criterion Number & df & t & p \\
IP & $0 / 80$ & $0 / 65$ & 0 & 107 & $12 / 78$ & $0.001^{*}$ \\
FL & $0 / 53$ & $0 / 50$ & 0 & 107 & $11 / 06$ & $0.001^{*}$ \\
\hline *One Sample t- test; $p \leq 0 / 05$ & & & & &
\end{tabular}

Table 4. Comparison between mean ratios of facial and intraoral anatomic landmarks with facial midlines in males and females

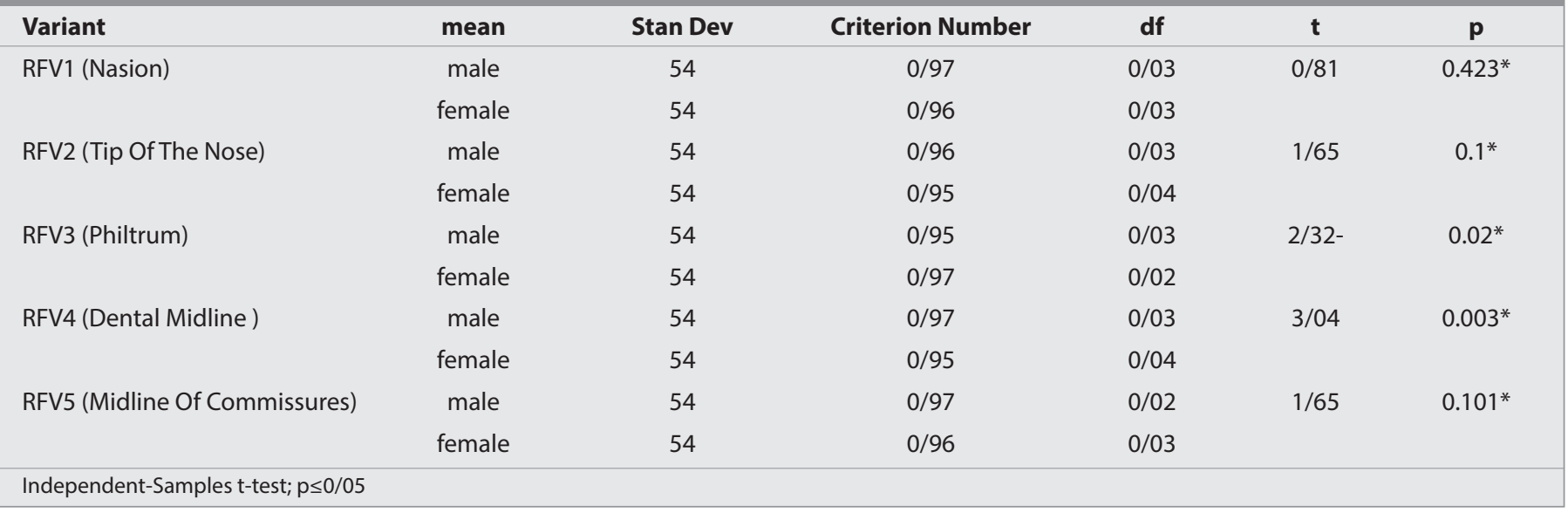

Table 5. Comparison between mean ratios of facial and intraoral anatomic landmarks with commissural midlines in males and females

\begin{tabular}{|c|c|c|c|c|c|c|}
\hline Variant & mean & Stan Dev & Criterion Number & df & $\mathbf{t}$ & $\mathbf{p}$ \\
\hline \multirow[t]{2}{*}{ RCV1 (Nasion) } & male & 54 & $0 / 94$ & $0 / 04$ & $-0 / 794$ & $0.429^{*}$ \\
\hline & female & 54 & $0 / 94$ & $0 / 05$ & & \\
\hline RCV2 (Tip of the nose) & female & 54 & $0 / 96$ & $0 / 04$ & & \\
\hline RCV3 (Philtrum) & male & 54 & $0 / 95$ & $0 / 03$ & $-0 / 067$ & $0.947^{*}$ \\
\hline RCV4 (Dental midline ) & female & 54 & $0 / 96$ & $0 / 04$ & & \\
\hline
\end{tabular}

Table 6. Comparison between mean intraoral anatomical landmarks and dental midlines in males and females

\begin{tabular}{|c|c|c|c|c|c|c|}
\hline Variant & mean & Stan Dev & Criterion Number & df & $\mathbf{t}$ & $\mathbf{p}$ \\
\hline \multirow[t]{2}{*}{ IP } & male & 54 & $0 / 58$ & $0 / 54$ & $1 / 030$ & $0.305^{*}$ \\
\hline & female & 54 & $0 / 48$ & $0 / 45$ & & \\
\hline $\mathrm{FL}$ & female & 54 & $0 / 74$ & $0 / 64$ & & \\
\hline
\end{tabular}

aggravate, they tend to be more sensitive than dentists $(11,14)$. Moreover, lay people are able to discern the discrepancy of axial dental midline angulation as low as $3.5^{\circ}$, and this is aggravated by having chin or nose deviation in the opposite direction and vice versa (15). However, further investigations are still needed to determine whether it is more pleasant to have a slight dental midline deviation in the same direction in subjects bearing chin and nose deviation; if it is yes, then how much?

Even people from different cultures have different sensitivities to midline discrepancies $(16,17)$. The investigation of the relation- ship between the facial and dental communication lines using the esthetic frame represents the deviation from the ideal symmetry and thus helps to improve the treatment plan (7). Midline problems are not related to age and sex (11). Facial midlines were defined by using the esthetic frame named by Bidra (7). The esthetic frame was designed to analyze the problems caused by the lack of an attractive smile. In the present study, the NHP was used and controlled by a trained researcher because it is valid and reliable, and it is absolutely necessary to avoid turning the head of the subjects around the vertical axis $(18,19)$. Nevertheless, human error in detecting this rotation should not be com- 
pletely ruled out. The smile's image was selected while none of the cases have a highly asymmetrical smile or a smile that does not show the maxillary central incisors. The study was designed to be completely clinically applicable. Thus, the markings of each anatomical landmark were done clinically (and not on a digital image), and the connecting lines were drawn along these markings. Despite the high precision, inherent human errors in marking anatomical landmarks cannot be ignored. Among the clinical landmarks, it was difficult to mark the nasion soft tissue and nasal tip for nasal anatomy reasons. Therefore, caution must be taken when using the results of these landmarks, and more studies should be conducted. There was a significant difference between the mean ratios of the selected anatomical landmark and facial midline in the evaluation of the facial midline and anatomical landmarks. Commissural midline was considered as an anatomical landmark when analyzing the hierarchical arrangement for midline that had the first rank in matching with the facial midline. Similar findings have also been found in studies conducted by Moshkelgosha et al. (20), Bidra et al. (7), and Kurian et al. (21), which may be due to the use of the concept of the esthetic frames in aforementioned studies. Nasion has a good position during the mid-fifth, but its relationship with the midline of the face and the commissural midline has not been studied much. However, in the present study, nasion is in the second rank in order of proximity to the facial midline, but due to the difficulty in clinical marking and its distances from the dental midline, it may compromise the results, so it cannot be a good clinical indicator for analyzing each of the midlines. In many previous studies, the philtrum or vermilion border was used to provide facial form, and due to its results and its position, it could be a reliable landmark for midline analysis $(1,9,10,12,22)$. In the present study, philtrum was ranked third in order of proximity to the midline. The dental midline was also considered as a landmark when analyzing the hierarchy order, and its relationship to the facial midline was evaluated. However, the vertical angle of the dental midline was not considered in the analysis. Dental midline was ranked last in order of proximity to the facial midline. In addition, in the present study, there was a significant difference between the mean of the philtrum and dental midline indices in males and females, which requires further studies to confirm the results. The second part of the study examines the proximity and hierarchy order of anatomical indices to the commissural midline (center of the mouth). Dental midline at the highest level and then philtrum, nasal tip, and nasion were closest to the commissural midline, respectively. In the present study, philtrum was ranked second in the hierarchy order, indicating that the philtrum is a more reliable indicator for the determination of the oral midline. In the present study, a significant difference was found between male and female subjects in relation to the commissural midline only in the nasal tip index, but in other indices, there was no significant difference in the need for further studies to confirm the results.

The third part of the study evaluated the relationship between the anatomical landmarks of the incisive papilla and labial frenum with the dental midline and found that there was a significant difference between the mean deviation of these two anatomical landmarks and the dental midline. The labial frenum with a mean deviation of $0.53 \mathrm{~mm}$ in comparison with the incisive papilla with an average deviation of $0.80 \mathrm{~mm}$ was closer to the dental midline. McVay et al. (18) reported that the mean deviation of the labial frenum from the midline is $0.93 \mathrm{~mm}$, but the labial frenum is less deviated from the midline than the incisive papilla (18). The average deviation cannot be compared with other previous studies that measured measurements manually from the casts owing to the method used in the present study and the magnification in the preparation of digital images, and more studies need to be conducted. According to some researcher's belief, in determining the position of the frenum, a very precise dental cast is required ( 5 , 15). In the present study, it was attempted to observe the position of the frenum and then take the dental impression precisely, and the cast pouring was carefully done to prevent the frenum from bubbling or fracturing. During the capturing of digital images, it was also very important to record the marked lines on the frenum at the maximum resolution and the smallest magnification. In addition, inherent human errors cannot be ignored. Despite all of the above, the results of the present study and other studies were conducted with regard to the lack of significant superiority of the incisive papilla, and if it was possible to record the labial frenum accurately, it could be described as a more appropriate landmark. However, the labial frenum, which is more often referred to as a reliable key indicator for determining the position of the maxillary central incisors, is used.

\section{CONCLUSION}

In the present study, the following conclusions were achieved:

- The hierarchy of the facial anatomical landmarks closest to the midline of the face was as follows: commissural midline, nasion, philtrum, and dental midline.

- With consideration of the commissural midline, the hierarchy of the facial anatomical landmarks closest to it was as follows: dental midline, philtrum, nasal tip, and nasion.

- If an impression record is taken accurately, the labial frenum could be described as a more appropriate landmark and is more often referred to as a reliable key indicator for determining the position of the maxillary central incisors.

Ethics Committee Approval: Ethics committee approval was received for this study from the Ethics Committee of Ardabil University of Medical Sciences.

Informed Consent: Written informed consent was obtained from the patients who participated in this study.

Peer-review: Externally peer-reviewed.

Author Contributions: Concept - K.J.; Design - A.F.; Supervision - K.J, A.H.; Materials - A.F., K.J.; Data Collection and/or Processing - A.F., M.H.F., A.H.; Analysis and/or Interpretation - A.F., A.N.; Literature Search - A.F., A.H., R.N.; Writing Manuscript - A.F., M.H.F.; Critical Review - M.H.F, A.F, A.H., R.N.

Conflict of Interest: The authors have no conflict of interest to declare. 
Financial Disclosure: The authors declared that this study has received no financial support.

\section{REFERENCES}

1. Beyer JW, Lindauer SJ, editors. Evaluation of dental midline position. Seminars in orthodontics; 1998: Elsevier. [CrossRef]

2. Khan M, Qamar K, NAEEM S. Coincidence of facial midline with dental midline. Pak Oral Dental J 2014; 34: 355-17.

3. Merriam-Webster's Dictionary. 9th ed. Springfield, MA: Merriam-Webster; 1984.p:807.

4. Bishara SE, Burkey PS, Kharouf JG. Dental and facial asymmetries: a review. Angle Orthod 1994; 64: 89-98.

5. Rostamkhany F, Asadzadeh Aghdaee N, Esmaily H. Evaluation of relationship between length and width of natural maxillary central and lateral incisors, and some measurable parameters of the face. J Mash Dent Sch 2005; 29: 209-14.

6. Zarb GA, Bolender CL, Eckert S, Jacob R, Mericske-Stern R. Prosthodontic treatment for edentulous patients. Mosby 2004; 12: 195-7.

7. Bidra AS, Uribe F, Taylor TD, Agar JR, Rungruanganunt P, Neace WP. The relationship of facial anatomic landmarks with midlines of the face and mouth. J Prosthet Dent 2009; 102: 94-103. [CrossRef]

8. Eskelsen E, Fernandes CB, Pelogia F, Cunha LG, Pallos D, Neisser MP, et al. Concurrence between the maxillary midline and bisector to the interpupillary line. J Esthet Restor Dent 2009; 21: 37-41. [CrossRef]

9. Latta GH. The midline and its relation to anatomic landmarks in the edentulous patient. J Prosthet Dent 1988; 59: 681-3. [CrossRef]

10. Johnston CD, Burden DJ, Stevenson MR. The influence of dental to facial midline discrepancies on dental attractiveness ratings. Eur J Orthod 1999; 21: 517-22. [CrossRef]

11. Kokich Jr VO, Asuman Kiyak H, Shapiro PA. Comparing the perception of dentists and lay people to altered dental esthetics. J Esthet Restor Dent 1999; 11: 311-24. [CrossRef]
12. Miller EL, Bodden Jr WR, Jamison HC. A study of the relationship of the dental midline to the facial median line. J Prosthet Dent 1979; 41:657-60. [CrossRef]

13. Owens EG, Goodacre CJ, Loh PL, Hanke G, Okamura M, Jo K-h, et al. A multicenter interracial study of facial appearance. Part 2: A comparison of intraoral parameters. Int J Prosthodont 2002; 15: 283-8.

14. Rosenstiel SF, Rashid RG. Public preferences for anterior tooth variations: a web-based study. J Esthet Restor Dent 2002; 14: 97-106. [CrossRef]

15. Silva BP, Jiménez-Castellanos E, Stanley K, Mahn E, Coachman C, Finkel S. Layperson's perception of axial midline angulation in asymmetric faces. J Esthet Restor Dent 2018; 30: 119-25. [CrossRef]

16. Haghighi AH, Zarghami A, Sadrhaghighi S, Mohammadi A, Eskandarinezhad M. Esthetic preferences of laypersons of different cultures and races with regard to smile attractiveness Indian J Dent Res 2017; 28: 156.

17. Akinboboye B, Umesi D, Esan T. Perception of midline diastema in dental-and nondental-oriented individuals. Sahel Med J 2018; 21: 104-8. [CrossRef]

18. McVay $T$, Latta $G$. Incidence of the maxillary midline diastema in adults. J Prosthet Dent 1984; 52: 809-11. [CrossRef]

19. Peng L, Cooke MS. Fifteen-year reproducibility of natural head posture: a longitudinal study. Am J Orthod 1999; 116: 82-5. [CrossRef]

20. Moshkelgosha V, Zare R, Safari A. Software designation to assess the proximity of different facial anatomic landmarks to midlines of the mouth and face. JDB 2014; 1: 50-6.

21. Kurian N, Gandhi N, Daniel AY, Varghese VS, Daniel S, Mehdiratta S. Digital analysis of facial landmarks in determining facial midline among Punjabi population. CHRISMED J Health Res 2018; 5: 99-104. [CrossRef]

22. Cardash HS, Ormanier Z, Laufer BZ. Observable deviation of the facial and anterior tooth midlines. J Prosthet Dent 2003; 89: 282-5. [CrossRef] 